\title{
Derin kazı destek sistemlerinin analizinde geoteknik modelleme farklılıkları
}

\author{
Vedat ASLAN ${ }^{1,}$, Banu YAĞCI ${ }^{2 *}$ \\ ${ }^{1}$ Kepsut Belediyesi, Balıkesir. \\ ${ }^{2}$ Balıkesir Üniversitesi Mühendislik Fakültesi, İnşaat Mühendisliği Bölümü, \\ Çă̆ış Kampüsü, Balıkesir. \\ Geliș Tarihi (Recived Date): 09.07.2017 \\ Kabul Tarihi (Accepted Date): 24.03.2018
}

\section{Özet}

Bu çalışmada, Balıkesir'deki bir inceleme alanı için geoteknik modelleme ve destek sistemleri tasarımını amaçlayan parametrik analizler yapılmıştır. Mevcut veri doğrultusunda alternatif geoteknik modeller oluşturulmuş ve modelleme farklılıklarının deformasyon analizleri üzerindeki etkisi incelenmiştir. Farklı derinliklerdeki kazllar için, konsol ve ankrajl destek sistemlerinin tasarımları Geo5 programı ile, deformasyon analizleri ise hem Geo5 hem de Plaxis programı ile yapılmıştır. Hesap yöntemleri açısından farklı iki ayrı yazılımın kullanılması, modellemenin geoteknik uygulamaların performansı üzerinde önemli oranda etkili olduğunu göstermiştir.

Anahtar kelimeler: Balıkesir, Geo5, plaxis, geoteknik model, diyafram duvar, ankraj.

\section{Geotechnical modeling differences in the analysis of deep excavation support systems}

\begin{abstract}
In this study, parametric analysis for geotechnical modeling and design support systems are carried out for a study area in Balıkesir. Alternative geotechnical models were established in the direction of existing data and the effect of modeling differences on deformation analysis was examined. For excavations at different depths, the designs of the cantilever and anchorage support systems were done with the Geo5 program, and deformation analyzes were performed with the Geo5 and Plaxis programs. The use of two different softwares in terms of calculation methods has shown that the model has a significant impact on the performance of geotechnical applications.
\end{abstract}

Vedat ASLAN, vedat.aslan27@ @otmail.com, http://orcid.org/0000-0001-6996-3815

*Banu YAĞCI, byagci@balikesir.edu.tr, http://orcid.org/0000-0002-3261-2680 
Keywords: Balikesir, Geo5, plaxis, geotechnical model, diaphragm wall, anchorage.

\section{Giriş}

Literatürdeki derin kazı destek sistemleri ile ilgili zemin sınıfı farklılıklarının incelendiği parametrik bazı çalışmalar mevcuttur [1-4]. Diğer yandan vaka analizlerinde, hesapla bulunan ve ölçülen sonuçların uyumsuz olması gibi nedenlerle, referans çözümler dışında parametrik analizler de yapılmaktadır [5-10]. Geoteknik mühendisliği uygulamalarında performansı etkileyen faktörlerin başında, geoteknik araştırmaların ve dolayısıyla bu araştırma sonuçlarına dayanan geoteknik modellemelerin geldiği söylenebilir. Bu açıdan literatürdeki çalışmaların bir bölümünü de zemin parametrelerindeki belirsizliğin/değişimin göz önüne alınabileceği yaklaşımlar oluşturmaktadır [11-14]. Bu çalışmada, Balıkesir'deki bir inceleme alanı için mevcut veri doğrultusunda alternatif geoteknik modeller oluşturulmuş ve modelleme farklılıklarının deformasyon analizleri üzerindeki etkisi incelenmiştir.

$\mathrm{Bu}$ alandaki deformasyon analizleri sonlu elemanlar yöntemlerini kullanan programlar ile yapılmaktadır. $\mathrm{Bu}$ yöntemler ile zemin-yapı etkileşimini daha gerçekçi modelleyerek destek sistemlerinin yapım aşamalarını da dikkate almak mümkün olmaktadır. Ancak sistemin öncelikle "Limit Denge" ya da "Elastik Zemine Oturan Kiriş" gibi daha basit analiz yöntemlerine dayalı olarak tasarlanması veya sonuçların basit yöntemler ile de kontrol edilmesi önerilmektedir. Bu çalışmada konsol ve ankrajlı destek sistemlerinin tasarımları Geo5 programı [15] ile, deformasyon analizleri ise hem Geo5 hem de Plaxis programı [16] ile yapılmıştır. Hesap yöntemleri açısından farklı iki ayrı yazılımın kullanılmış olması, modellemenin geoteknik uygulamaların performansı üzerinde önemli oranda etkili olduğunu göstermiştir.

\section{Geoteknik veri}

İnceleme alanı alüvyon tanımlı bölgede yer almakta olup neojen tortullarla çevrilidir. Sondajlarda $13 \mathrm{~m}$ derinliğe kadar kuvaterner yaşlı alüvyonel birimler ve bu seviyeden sonra ise neojen yaşlı sedimanter ve volkanosedimanter birimler tanımlanmıştır (Şekil 1). "Kumlu killi çakıl” tanımlı tabaka (SC-GC) için yapılmış zemin sınıflandırma deneyleri sonuçlarına göre; ince malzeme oranları GC zeminde \% 21-\% 47 arasında, SC zeminde \%40-\%45 arasındadır. İnce malzemenin plastisite indisi PI=14 dür. Bölgede yeraltı suyu 3,5 m seviyesindedir. Mevcut standart penetrasyon ve serbest basınç deney sonuçları Şekil 1'de gösterilmiştir [17].

\section{Konsol destek sistemi için analizler}

$\mathrm{H}=4 \mathrm{~m}$ kazı derinliğine sahip konsol destek sistemi için $\mathrm{d}=0,6 \mathrm{~m}$ kalınlığında diyafram duvar kabulü yapılmıştır. Analizlerde, Geo5 programının "Perde Tasarımı" bileşeni ile farklı sürşarj yükleri altında, Eurocode EN1997-DA3 tahkik yöntemi kullanılarak duvar gömülme derinlikleri hesaplanmıştır. 

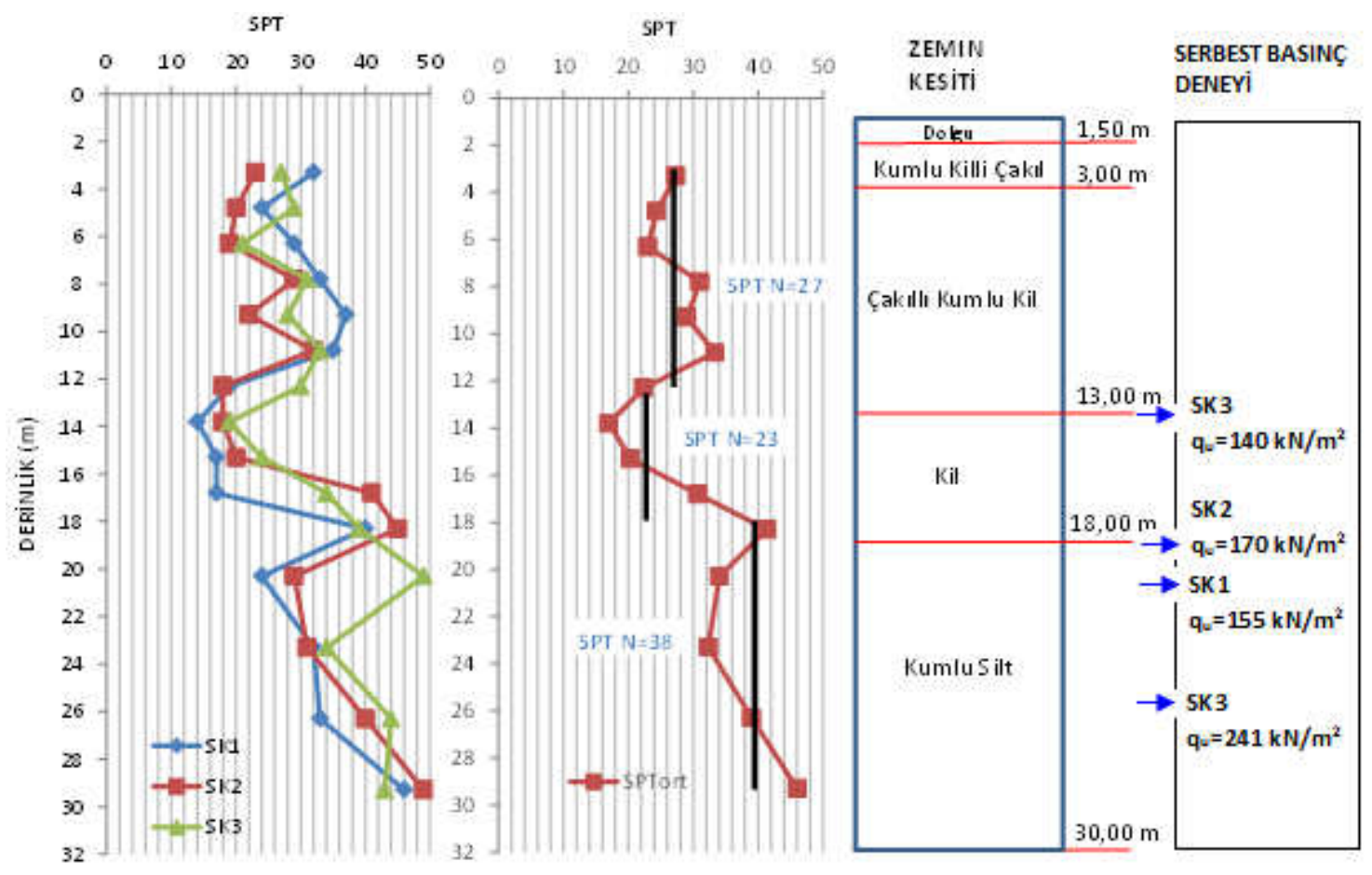

Şekil 1. İnceleme alanı zemin profili.

Geoteknik veriye dayalı olarak homojen zemin kabulü ile iki ayrı model göz önüne alınmıştır: Laboratuvar deneylerini göz önüne alan drenajsız zemin parametrelerine dayalı modelde, kohezyon değerleri serbest basınç direncine dayalı olarak ve elastisite modülü değerleri amprik olarak, $\left(\mathrm{E}_{\mathrm{u}}=250-500 \mathrm{c}_{\mathrm{u}}\right.$ ) (Das, 1998 ) ile belirlenmiştir (Tablo 1) [18]. Efektif parametrelere dayalı modelde, Geo5 veri tabanında "orta plastisiteli, orta kat1-katı kıvamdaki kil” için önerilen zemin parametreleri seçilmiştir (Tablo 2).

Tablo 1. Drenajsız zemin parametreleri.

\begin{tabular}{|c|c|c|c|c|c|c|c|}
\hline \multicolumn{8}{|c|}{ Geo5 zemin parametreleri } \\
\hline & & \multicolumn{3}{|c|}{ Perde Tasarımı Parametreleri } & \multicolumn{3}{|c|}{$\begin{array}{l}\text { Perde Kontrolü Ek Parametreleri } \\
{\left[\mathrm{K}_{\mathrm{h}} \text { için otomatik iterasyon yaklaşımı ile }\right]}\end{array}$} \\
\hline \multicolumn{2}{|c|}{ Zemin } & $\begin{array}{l}\gamma_{\mathbf{n}} \\
\text { Birim Hacim } \\
\text { Ağıllık } \\
\left(\mathrm{kN} / \mathrm{m}^{3}\right)\end{array}$ & $\begin{array}{l}\mathbf{c}_{\mathbf{u}} \\
\text { Kohezyon } \\
\left(\mathrm{kN} / \mathrm{m}^{2}\right)\end{array}$ & $\begin{array}{l}\text { a } \\
\text { Adhezyon } \\
\left(\mathrm{kN} / \mathrm{m}^{2}\right)\end{array}$ & $\begin{array}{l}\mathbf{E}_{\mathbf{u}} \\
\text { Elastisite } \\
\text { Modülü } \\
\left(\mathrm{kN} / \mathrm{m}^{2}\right)\end{array}$ & $\begin{array}{l}\mathbf{v} \\
\text { Poisson } \\
\text { Oran1 }\end{array}$ & $\begin{array}{l}\mathbf{m} \\
\text { Yapisal Dayanım } \\
\text { Katsayis1 }\end{array}$ \\
\hline \multicolumn{2}{|c|}{ CI-CL } & 21 & 70 & 35 & 17500 & 0,49 & 0,2 \\
\hline \multicolumn{8}{|c|}{ Plaxis zemin parametreleri } \\
\hline (m) & Zemin & $\begin{array}{l}\gamma_{\mathrm{n}} \\
\text { Birim Hacim } \\
\text { Ağırlık } \\
\left(\mathrm{kN} / \mathrm{m}^{3}\right)\end{array}$ & $\begin{array}{l}\mathbf{c}_{\mathrm{u}} \\
\text { Kohezyon } \\
\left(\mathrm{kN} / \mathrm{m}^{2}\right)\end{array}$ & $\begin{array}{l}\mathbf{R}_{\text {int }} \\
\text { Arayüzey } \\
\text { Rijitlik } \\
\text { azalım } \\
\text { katsayıs1 }\end{array}$ & $\begin{array}{l}\mathbf{E}_{\mathbf{u}} \\
\text { Elastisite } \\
\text { Modülü } \\
\\
\left(\mathrm{kN} / \mathrm{m}^{2}\right)\end{array}$ & $\begin{array}{l}\boldsymbol{v} \\
\text { Poisson } \\
\text { Oranı }\end{array}$ & Drenaj Koşulu \\
\hline 40 & Kil & 21 & 70 & $\mathbf{0 , 7 0}$ & 17500 & $\mathbf{0 , 5 0}$ & Drenajsız $(\mathbf{C})$ \\
\hline
\end{tabular}

Geo5 tasarımında sürşarj yükü arttıkça gömülme derinliği de artmaktadır. Bu doğrultuda Plaxis analizlerinde, $\mathrm{q}=100 \mathrm{kPa}$ için hesaplanmış olan maksimum gömülme derinlikleri kullanılmıştır (Tablo 3-4). 
Tablo 2. Efektif zemin parametreleri.

\begin{tabular}{|c|c|c|c|c|c|c|c|c|}
\hline \multicolumn{9}{|c|}{ Geo5 zemin parametreleri } \\
\hline & & \multicolumn{3}{|c|}{ Perde Tasarımı Parametreleri } & \multicolumn{4}{|c|}{$\begin{array}{l}\text { Perde Kontrolü Ek Parametreleri } \\
{\left[\mathrm{K}_{\mathrm{h}} \text { için otomatik iterasyon yaklaşımı ile] }\right.}\end{array}$} \\
\hline & Zemin & $\begin{array}{l}\gamma_{\mathbf{n}} \\
\text { Birim } \\
\text { Hacim } \\
\text { Ağırlık } \\
\left(\mathrm{kN} / \mathrm{m}^{3}\right)\end{array}$ & $\begin{array}{l}\mathbf{c}^{\prime} \\
\text { Kohezyon } \\
\left(\mathrm{kN} / \mathrm{m}^{2}\right)\end{array}$ & $\begin{array}{l}\phi ’ \\
\phi^{\prime} \\
\text { Icçsel } \\
\text { Sürtünme } \\
\text { Aç1s1 } \\
\left(^{\circ}\right)\end{array}$ & $\begin{array}{l}\delta \\
\text { Duvar-Zemin } \\
\text { Sürtünme } \\
\text { Aç1s1 } \\
\left(^{\circ}\right)\end{array}$ & $\begin{array}{l}\mathbf{E} \\
\text { Elastisite } \\
\text { Modülü } \\
\left(\mathrm{kN} / \mathrm{m}^{2}\right)\end{array}$ & $\begin{array}{l}\mathbf{v} \\
\text { Poisson } \\
\text { Oranı }\end{array}$ & \begin{tabular}{|l}
$\mathbf{m}$ \\
Yapısal \\
Dayanım \\
Katsayısı
\end{tabular} \\
\hline & CI-CL & 21 & 16 & 19 & 12 & 7000 & $\mathbf{0 , 4 0}$ & 0,2 \\
\hline \multicolumn{9}{|c|}{ Plaxis zemin parametreleri } \\
\hline (m) & Zemin & $\begin{array}{l}\gamma_{\mathbf{n}} \\
\text { Birim } \\
\text { Hacim } \\
\text { Ağırlık } \\
\left(\mathrm{kN} / \mathrm{m}^{3}\right)\end{array}$ & $\begin{array}{l}\mathbf{c}^{\prime} \\
\text { Kohezyon } \\
\left(\mathrm{kN} / \mathrm{m}^{2}\right)\end{array}$ & $\begin{array}{l}\phi \\
\text { '̇çsel } \\
\text { Sürtünme } \\
\text { Açıs1 } \\
\left(^{\circ}\right)\end{array}$ & $\begin{array}{l}\mathbf{R}_{\text {int }} \\
\text { Arayüzey } \\
\text { Rijitlik azalım } \\
\text { katsayıs1 }\end{array}$ & $\begin{array}{l}\text { E' } \\
\text { Elastisite } \\
\text { Modülü } \\
\left(\mathrm{kN} / \mathrm{m}^{2}\right)\end{array}$ & $\begin{array}{l}\mathbf{v} \\
\text { Poisson } \\
\text { Oranı }\end{array}$ & Drenaj Koşulu \\
\hline 40 & Kil & 21 & 16 & 19 & $\mathbf{0 , 7 0}$ & 7000 & $\mathbf{0 , 4 0}$ & Drenajsız (A) \\
\hline
\end{tabular}

Tablo 3. Drenajsız parametreler ile analiz sonuçları.

\begin{tabular}{|l|c|c|c|c|}
\hline & $\begin{array}{c}\mathbf{q} \\
\left(\mathrm{kN} / \mathrm{m}^{2}\right)\end{array}$ & $\begin{array}{c}\mathbf{D} \\
(\mathrm{m})\end{array}$ & $\begin{array}{c}\mathbf{u}_{\text {xmaks. }} \\
(\mathrm{mm})\end{array}$ & $\mathbf{u}_{\mathbf{x m a k s .}} / \mathbf{H}$ \\
\hline Geo5 Tasarım ve Analiz sonuçları & $20-60$ & 2 & 37.5 & 0,009 \\
\cline { 2 - 5 } & 100 & 4.5 & 36 & 0,009 \\
\hline Plaxis Analiz sonuçları \\
(Drenajsız Analiz)
\end{tabular}

Tablo 4. Efektif parametreler ile analiz sonuçları.

\begin{tabular}{|l|c|c|c|c|}
\hline & $\begin{array}{c}\mathbf{q} \\
\left(\mathrm{kN} / \mathrm{m}^{2}\right)\end{array}$ & $\begin{array}{c}\mathbf{D} \\
(\mathrm{m})\end{array}$ & $\begin{array}{c}\mathbf{u}_{\text {xmaks. }} \\
(\mathrm{mm})\end{array}$ & $\mathbf{u}_{\mathbf{x m a k s .}} / \mathbf{H}$ \\
\hline Geo5 Tasarım ve Analiz sonuçları & 20 & 6 & 13 & 0,0034 \\
\cline { 2 - 5 } & 60 & 11 & 40 & 0,010 \\
\cline { 2 - 5 } & 100 & 15 & 117 & 0,030 \\
\hline Plaxis Analiz sonuçları \\
(Drenajsız Analiz) & 20 & 15 & 216 & $\mathbf{0 , 0 5 4}$ \\
\cline { 2 - 5 } & 60 & 15 & 339 & $\mathbf{0 , 0 8 5}$ \\
\cline { 2 - 5 } & 100 & 15 & 670 & $\mathbf{0 , 1 6 8}$ \\
\hline
\end{tabular}

Plaxis analiz sonuçları, drenajsız analizde, $\mathrm{H}=4 \mathrm{~m}$ kazı derinliği göz önüne alındığında, trafik ya da tek katlı hafif yapılar için varsayılabilecek $q=20 \mathrm{kPa}$ 'lık sürşarj yükünde dahi duvarda gözlenen maksimum deplasman oranları $\left(\mathrm{u}_{\mathrm{xmaks}} / \mathrm{H}\right)$ cinsinden, konsol destek sisteminin yeterli olmayacağını göstermektedir. Diğer yandan, efektif zemin parametreleri ile modellenen koşullarda, drenajsız parametreler ile modellenen koşullara göre duvarda gözlenen maksimum deplasman oranları daha yüksek belirlenmiştir.

$\mathrm{Bu}$ sonuçlar doğrultusunda; en olumsuz koşul $(\mathrm{q}=100 \mathrm{kPa})$ göz önüne alınarak, duvar kalınlığının değiştirilmesi $(\mathrm{d}=1,2 \mathrm{~m})$ ve homojen kabul edilen zemin tabakasında rijitlik parametresinin derinlik ile artırılması varsayımı ile bir Plaxis analizi daha yapılmıștır. $\mathrm{Bu}$ amaçla idealize edilmiş zemin profili modelinden faydalanılmış ve $\mathrm{z}=18 \mathrm{~m}$ 
derinlikten den sonra, E elastisite modülünün her 1 m'de $500 \mathrm{kPa}$ arttığı varsayımı yapılmıştır. Bu varsayım altında Plaxis ile yapılan analiz sonucu, duvardaki maksimum deplasman $\mathrm{u}_{\mathrm{xmaks}}=193 \mathrm{~mm}$ hesaplanmıştır. Bu yaklaşım deplasmanları yaklaşı üçte iki oranında düşürmesine rağmen, konsol sistemin uygulanabilirliği modellenen zemin koşullarında halen mümkün görülmemektedir.

\section{Tek sıra ankrajlı destek sistemleri için analizler}

$\mathrm{H}=4 \mathrm{~m}$ kazı derinliğinde, tek sıra ankrajlı, $\mathrm{d}=0,6 \mathrm{~m}$ kalınlığındaki diyafram duvarın Geo5 programı ile tasarımında; Eurocode EN1997-DA3 tahkik yöntemi kullanılarak duvar gömülme derinliği ve ankraj kuvvetleri hesaplanmış ve zemin yatak katsayısı için otomatik iterasyon yaklaşımı ile deplasman ve içsel stabilite kontrolleri yapılmıştır.

$\mathrm{Bu}$ aşamada analizler efektif parametrelere dayalı modeller ile yapılmıştır (Tablo 5). Model-1, Geo5 veri tabanından zemin cinsi ve kıvamına göre önceki bölümde belirlenmiş olan modeldir. Model-2'de; Terzaghi vd. (1996) ilişkisi kullanılarak plastisite indisi $\mathrm{I}_{\mathrm{p}}=14$ için içsel sürtünme açısı $\phi^{\prime}=30^{\circ}$ belirlenmiş ve kohezyon literatürde yer alan pratikteki deneyimlere dayalı olarak c' $=10 \mathrm{kPa}$ seçilmiştir [18-19]. Model-2 için elastisite modülü,

$$
E^{\prime}=\frac{2\left(1+\vartheta^{\prime}\right)}{3} E_{u}=\frac{2(1+0,4)}{3} 17,5 \cong 15 \mathrm{MPa}
$$

ilişkisi ile belirlenmiştir

Tablo 5. Geo5 efektif zemin parametreleri.

\begin{tabular}{|c|c|c|c|c|c|c|c|}
\hline & \multicolumn{3}{|c|}{ Perde Tasarımı Parametreleri } & \multicolumn{4}{|c|}{$\begin{array}{l}\text { Perde Kontrolü Ek Parametreleri } \\
{\left[\mathrm{K}_{\mathrm{h}} \text { için otomatik iterasyon yaklaşımı ile] }\right.}\end{array}$} \\
\hline CI-CL & $\begin{array}{l}\gamma_{\mathbf{n}} \\
\text { Birim } \\
\text { Hacim } \\
\text { A ğırlık } \\
\left(\mathrm{kN} / \mathrm{m}^{3}\right)\end{array}$ & $\begin{array}{l}\mathbf{c}^{\prime} \\
\text { Kohezyon } \\
(\mathrm{kPa})\end{array}$ & $\begin{array}{l}\phi ’ \\
\text { İçsel } \\
\text { Sürtünme } \\
\text { Açııs } \\
\left({ }^{\circ}\right)\end{array}$ & $\begin{array}{l}\delta \\
\text { Duvar-Zemin } \\
\text { Sürtünme } \\
\text { Aç1s1 } \\
\left({ }^{\circ}\right)\end{array}$ & $\begin{array}{l}\text { E' } \\
\text { Elastisite } \\
\text { Modülü } \\
\\
(\mathrm{MPa})\end{array}$ & $\begin{array}{l}\mathbf{v} \\
\text { Poisson } \\
\text { Oran1 }\end{array}$ & \begin{tabular}{|l} 
m \\
Yapısal \\
Dayanım \\
Katsayıs1
\end{tabular} \\
\hline Model-1 & 21 & 16 & 19 & 12 & 7 & $\mathbf{0 , 4 0}$ & 0,2 \\
\hline Model-2 & 21 & 10 & 30 & 20 & 15 & 0,40 & 0,2 \\
\hline
\end{tabular}

Seçilen ankraj parametreleri (Şekil 2) için Geo5 analiz sonuçları Tablo 6' da gösterilmiştir. Geo5 ile belirlenen duvardaki maksimum deplasmanlar, q=60 kPa'lık sürşarj yüküne kadar $\mathrm{H}=4$ m'lik bir kazı derinliğinde, tek ankrajlı destek sisteminin uygulanabilir olduğunu göstermektedir. Sürşarj yükünün q=100 kPa olması durumunda ise deplasmanların sınır değerleri aştığı görülmektedir. Model-2 için duvardaki maksimum deplasmanların, Model-1 için elde edilen deplasmanlara göre daha düşük olduğu belirlenmiştir. Diğer yandan, Model-1 ile yapılan analizler konsol sistem ile karşılaştırıldığında tek sıra ankraj konulmasının deplasmanları önemli oranda azalttığı söylenebilir. 


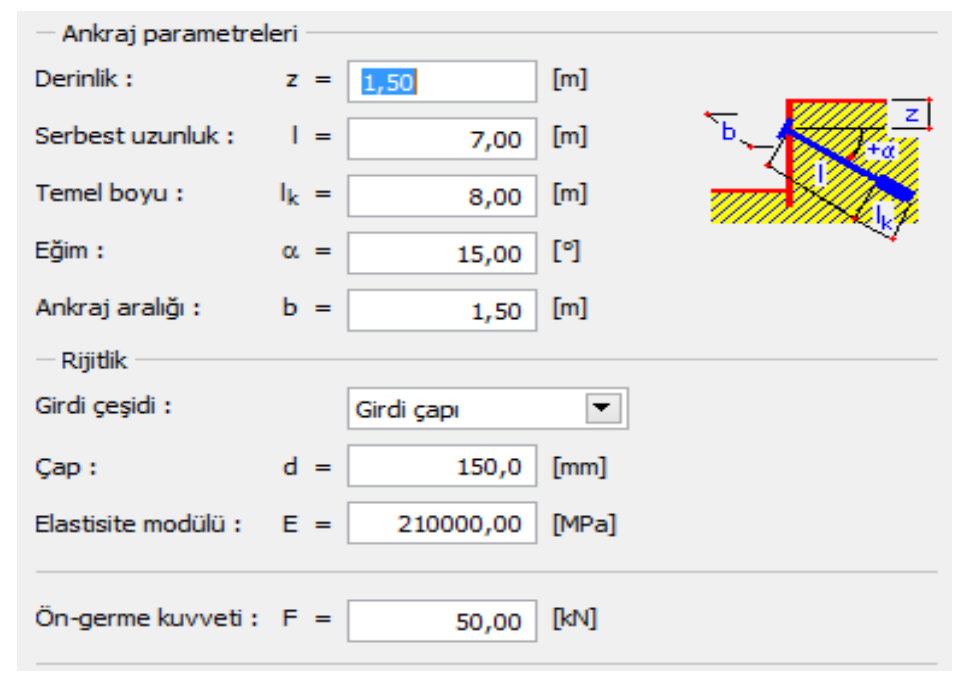

Şekil 2. Ankraj parametreleri.

Tablo 6. Tek sıra ankrajlı destek sistemleri için Geo5 analiz sonuçları.

\begin{tabular}{|c|c|c|c|c|c|c|c|c|c|c|}
\hline & \multicolumn{5}{|c|}{ Model-1 } & \multicolumn{5}{|c|}{ Model-2 } \\
\hline \multirow{2}{*}{ 䍖 } & \multirow{2}{*}{ 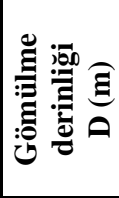 } & \multirow{2}{*}{ 蛋 } & \multirow{2}{*}{ 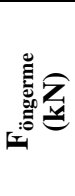 } & $\begin{array}{l}\mathbf{u}_{\text {xmaks. }} \\
(\mathbf{m m})\end{array}$ & \multirow{2}{*}{ 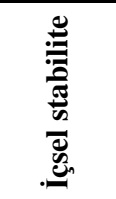 } & \multirow{2}{*}{ ڤ̊ } & \multirow{2}{*}{ 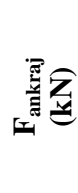 } & \multirow{2}{*}{ 童 } & \multirow{2}{*}{$\begin{array}{c}\begin{array}{c}\mathbf{u}_{\text {xmaks. }} \\
(\mathbf{m m})\end{array} \\
\mathbf{u}_{\text {xmaks. }} / \mathbf{H}\end{array}$} & \multirow{2}{*}{ 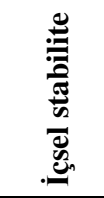 } \\
\hline & & & & $\mathbf{u}_{\text {xmaks. }} / \mathbf{H}$ & & & & & & \\
\hline \multirow[t]{2}{*}{20} & \multirow[t]{2}{*}{4} & \multirow[t]{2}{*}{50} & \multirow[t]{2}{*}{60} & 16,6 & \multirow{2}{*}{$\begin{array}{c}\% 14 \\
\mathrm{l}=7 \mathrm{~m} \\
\mathrm{l}_{\mathrm{k}}=8 \mathrm{~m}\end{array}$} & \multirow[t]{2}{*}{2,5} & \multirow[t]{2}{*}{43} & \multirow[t]{2}{*}{50} & 13,4 & \multirow{2}{*}{$\begin{array}{c}\% 7 \\
\mathrm{l}=7 \mathrm{~m} \\
\mathrm{l}_{\mathrm{k}}=8 \mathrm{~m}\end{array}$} \\
\hline & & & & 0,00415 & & & & & 0,00335 & \\
\hline \multirow[t]{2}{*}{40} & \multirow[t]{2}{*}{5} & \multirow[t]{2}{*}{107} & \multirow[t]{2}{*}{128} & 17,7 & \multirow{2}{*}{$\begin{array}{c}\% 35 \\
1=7 \mathrm{~m} \\
\mathrm{l}_{\mathrm{k}}=8 \mathrm{~m}\end{array}$} & \multirow[t]{2}{*}{3} & \multirow[t]{2}{*}{80} & \multirow[t]{2}{*}{96} & 14,5 & \multirow{2}{*}{$\begin{array}{c}\% 13 \\
1=7 \mathrm{~m} \\
\mathrm{l}_{\mathrm{k}}=8 \mathrm{~m}\end{array}$} \\
\hline & & & & 0,00443 & & & & & 0,00363 & \\
\hline \multirow[t]{2}{*}{60} & \multirow[t]{2}{*}{6} & \multirow[t]{2}{*}{176} & \multirow[t]{2}{*}{211} & 19,1 & \multirow{2}{*}{$\begin{array}{c}\% 35 \\
\mathrm{l}=10 \mathrm{~m} \\
\mathrm{l}_{\mathrm{k}}=8 \mathrm{~m}\end{array}$} & \multirow[t]{2}{*}{3} & \multirow[t]{2}{*}{119} & \multirow[t]{2}{*}{143} & 18,3 & $\% 18$ \\
\hline & & & & 0,00478 & & & & & 0,00458 & $\begin{array}{l}1=7 \mathrm{~m} \\
\mathrm{l}_{\mathrm{k}}=8 \mathrm{~m}\end{array}$ \\
\hline 100 & 8 & 327 & 392 & 32,7 & $\% 33$ & 4 & 200 & 240 & 26,7 & $\% 28$ \\
\hline & & & & 0,00818 & $\begin{array}{l}1=12 \mathrm{~m} \\
\mathrm{l}_{\mathrm{k}}=8 \mathrm{~m}\end{array}$ & & & & 0,00668 & $\begin{array}{l}1=7 \mathrm{~m} \\
\mathrm{l}_{\mathrm{k}}=8 \mathrm{~m}\end{array}$ \\
\hline
\end{tabular}

$\mathrm{Bu}$ sistemlerin Plaxis programı ile analizlerinde kazı genişliği $\mathrm{B}=30 \mathrm{~m}$ varsayılmış, model sınırları için $\mathrm{x}_{\text {maks. }}=100 \mathrm{~m}$ ve $\mathrm{y}_{\min }=-50 \mathrm{~m}$ seçilmiştir. Her bir model aynı zamanda "rijitlik parametresinin derinlik ile artırılması" varsayımı ile de çözülmüştür (Tablo 7-8).

Tablo 7. Plaxis programı ankraj parametreleri.

\begin{tabular}{|c|c|c|c|c|c|c|c|c|}
\hline \multicolumn{5}{|c|}{ Halat Kısmı } & \multicolumn{4}{|c|}{ Kök Kısmı } \\
\hline $\begin{array}{l}\text { L } \\
\text { Uzunluk } \\
\text { (m) }\end{array}$ & $\begin{array}{l}\text { A } \\
\text { Alan } \\
\left(\mathbf{m}^{2}\right)\end{array}$ & $\begin{array}{l}\text { E } \\
\text { Elastisite } \\
\text { Modülï } \\
\left(\mathbf{k N} / \mathbf{m}^{2}\right)\end{array}$ & $\begin{array}{l}\text { EA } \\
\text { Normal } \\
\text { Rijitlik } \\
(\mathbf{k N})\end{array}$ & $\begin{array}{l}\mathbf{L}_{\text {spacing }} \\
\text { Aralık } \\
\text { (m) }\end{array}$ & $\begin{array}{l}\mathbf{L}_{\text {kök }} \\
\text { Uzunluk } \\
\text { (m) }\end{array}$ & $\begin{array}{l}\text { D } \\
\text { Çap } \\
(\mathbf{m})\end{array}$ & $\begin{array}{l}\mathbf{E} \\
\text { Elastisite } \\
\text { Modüliü } \\
\left(\mathbf{k N} / \mathbf{m}^{2}\right)\end{array}$ & $\begin{array}{c}\mathbf{L}_{\text {spacing }} \\
\text { Aralık } \\
\text { (m) }\end{array}$ \\
\hline 8 & $2 \times 0.001$ & 210000000 & 42000 & 1.5 & 8 & 0.15 & 20000000 & 1.5 \\
\hline
\end{tabular}


Tablo 8. Tek sıra ankrajlı destek sistemleri için Plaxis analiz sonuçları.

\begin{tabular}{|c|c|c|c|c|c|c|}
\hline & \multicolumn{6}{|c|}{$\mathbf{u}_{\text {xmaks. }}(\mathbf{m m}) /\left(\mathbf{u}_{\text {xmaks. }} / \mathbf{H}\right)$} \\
\hline & \begin{tabular}{|l|} 
Drenajsız \\
Analiz \\
Efektif \\
parametrelerle
\end{tabular} & $\begin{array}{l}\text { Drenajsiz } \\
\text { Analiz } \\
\text { Efektif } \\
\text { parametrelerle } \\
\mathbf{y}_{\text {ref }}=18 \mathrm{~m} \\
\mathrm{E}_{\text {inc }}=500 \mathrm{kPa}\end{array}$ & \begin{tabular}{|l} 
Drenajsiz \\
Analiz \\
Drenajsız \\
parametrelerle
\end{tabular} & \begin{tabular}{|l|} 
Drenajsız \\
Analiz \\
Drenajsız \\
parametrelerle \\
$\mathbf{y}_{\text {ref }}=18 \mathrm{~m}$ \\
$\mathbf{E}_{\text {inc }}=500 \mathrm{kPa}$ \\
\end{tabular} & \begin{tabular}{|l|} 
Drenajlı \\
Analiz
\end{tabular} & $\begin{array}{l}\text { Drenajlı } \\
\text { Analiz } \\
y_{\text {ref }}=18 \mathrm{~m} \\
E_{\text {inc }}=500 \mathrm{kPa}\end{array}$ \\
\hline $\begin{array}{l}\text { Model-1 } \\
\mathrm{q}=20 \mathrm{kPa} \\
D=4 \mathrm{~m} \\
\mathrm{~F}=60 \mathrm{kN} \\
\mathrm{ls}=8 \mathrm{~m} \\
\mathrm{l}_{\mathrm{k}}=8 \mathrm{~m}\end{array}$ & $\begin{array}{l}81 \\
(0,0203)\end{array}$ & $\begin{array}{l}27 \\
(0,0068)\end{array}$ & $\begin{array}{l}36 \\
(0,0090)\end{array}$ & $\begin{array}{l}20 \\
(0,0050)\end{array}$ & $\begin{array}{l}53 \\
(0,0130)\end{array}$ & $\begin{array}{l}18 \\
(0,00450)\end{array}$ \\
\hline $\begin{array}{l}\text { Model-2 } \\
q=20 \mathrm{kPa} \\
D=2,5 \mathrm{~m} \\
\mathrm{~F}=50 \mathrm{kN} \\
\mathrm{ls}=8 \mathrm{~m} \\
\mathrm{l}_{\mathrm{k}}=8 \mathrm{~m}\end{array}$ & $\begin{array}{l}34 \\
(0,0085)\end{array}$ & $\begin{array}{l}18 \\
(0,0045)\end{array}$ & $\begin{array}{l}34 \\
(0,0085)\end{array}$ & $\begin{array}{l}20 \\
(0,0050)\end{array}$ & $\begin{array}{l}18 \\
(0,0045)\end{array}$ & $\begin{array}{l}11 \\
(0,00275)\end{array}$ \\
\hline
\end{tabular}

Model-1' için Plaxis programında drenajsız parametreler ile drenajsız analiz sonucu $\mathrm{u}_{\mathrm{xmaks}}=36 \mathrm{~mm}$ belirlenmiştir (Tablo 8). Bu sonucu Geo5 sonucu ile kıyaslayabilmek amacıyla, Geo5'de drenajsız parametreler ile toplam gerilme analizi yapılmış ve $\mathrm{u}_{\mathrm{xmaks} .}=12 \mathrm{~mm}$ hesaplanmıştır. Halbuki Plaxis analizlerinin $\mathrm{y}_{\mathrm{ref}}=18 \mathrm{~m}$ 'den sonra elastisite modülünün her 1 metrede $\mathrm{E}_{\text {inc }}=500 \mathrm{kPa}$ arttığ 1 varsayımı ile yapılması durumunda hesaplanan $u_{\text {xmaks. }}=20 \mathrm{~mm}$ değeri (Tablo 8) ile Geo5 sonuçlarıyla daha yakın olduğu düşünülebilir. Diğer yandan drenajsız analizlerde kullanılan "efektif parametre modeli" ile "drenajsız parametre modeli" sonuçlarının Model-2 için birbiriyle daha fazla uyumlu olduğu ve dolayısıyla Model-2'nin efektif parametrelere göre modelleme yaklaşımı açısından da uygun olduğu söylenebilir.

Plaxis analiz sonuçlarının Geo5 deplasman analizi sonuçları ile kıyaslanmasında; Geo5 in efektif parametreler ile drenajsız analiz yapamadığı göz önünde bulundurularak, sonuçlar Plaxis sonuçlarındaki drenajlı analizler ile karşılaştırılmıştır. Model-1için $u_{\text {xmaks. }}=16,6 \mathrm{~mm}\left(\right.$ Geo5) ve $u_{\text {xmaks. }}=53 \mathrm{~mm}$ (Plaxis) iken, Model-2 için $u_{\text {xmaks. }}=13,4 \mathrm{~mm}$ (Geo5) $\mathrm{u}_{\mathrm{xmaks}}=18 \mathrm{~mm}$ (Plaxis) dir (Tablo 6 ve Tablo 8). Bu sonuçların da Model-2 için Geo5 ve Plaxis sonuçlarının daha uyumlu olduğunu gösterdiği söylenebilir.

\section{4. Çok sıra ankrajlı destek sistemleri için analizler}

Çok sıra ankrajlı sistem için $\mathrm{H}=8 \mathrm{~m}$ kazı derinliği ve $\mathrm{d}=1 \mathrm{~m}$ diyafram duvar kalınlığ seçilmiş, Geo5 programında Eurocode EN1997-DA3 tahkik yöntemi için duvar gömülme derinliği ve ankraj kuvvetleri hesaplanarak, zemin yatak katsayısı için otomatik iterasyon yaklaşımı ile deplasman ve içsel stabilite kontrolleri Güvenlik katsayıs1 (ASD) ve Eurocode EN1997-DA3 tahkik yöntemleri ile yapılmıştır. q=20 kPa sürşarj yükü altındaki analizlerde, inceleme alanı için seçilmiş olan drenajsız parametre modeli (Tablo 1) ve iki ayrı efektif parametre modeli (Tablo 5) olmak üzere 3 zemin modeli kullanılmıştır. 
Çok sıra ankrajlı sistemler için Geo5 programında analizler, sonlu elamanlar yazılımlarındaki gibi zemin yapı etkileşimini göz önüne alan aşamalı inşaat yaklaşımı ile yapılmaktadır. Ankrajlar Şekil 3' de gösterilmiş olan geometride modellenmiştir.

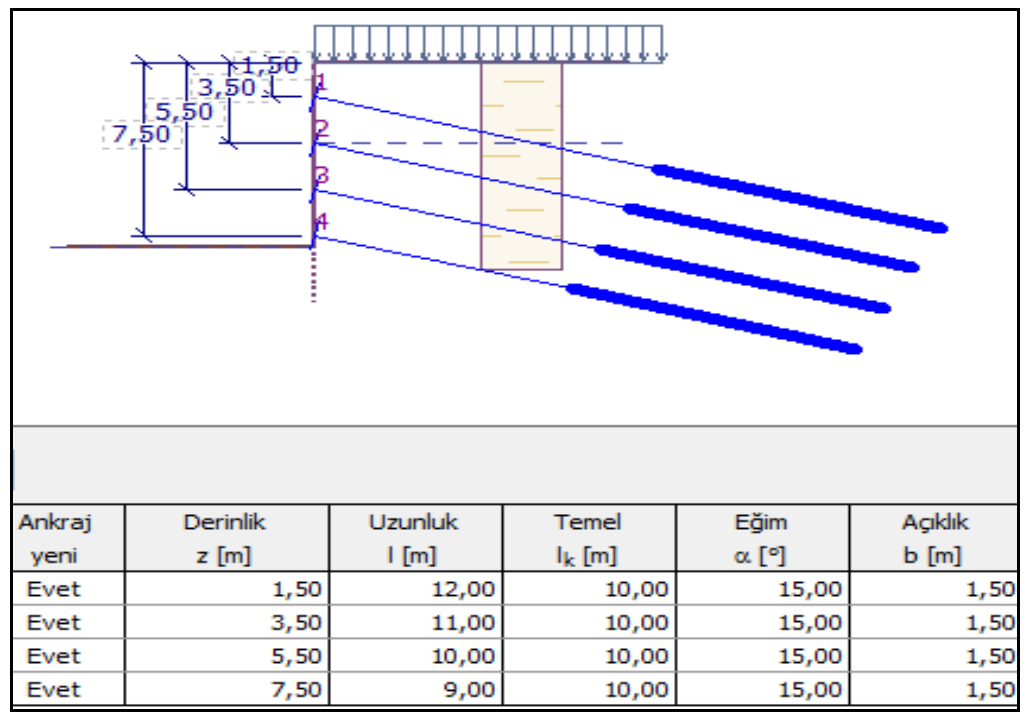

Şekil 3. Geo5 perde tasarımı model geometrisi (EN1997-DA3-Model-1).

Geo5 perde tasarımında belirlenen gömülme derinliği ve ankraj kuvvetleri (Şekil 4) için perde kontrolü programında 8 aşamalı olarak planlanan kazı destek sisteminin deformasyon ve içsel stabilite denge kontrolleri her bir aşama için yapılmaktadır (Şekil 5-6). Son aşama için destek sistemine ait sonuçlar Tablo 9' da gösterilmiştir.

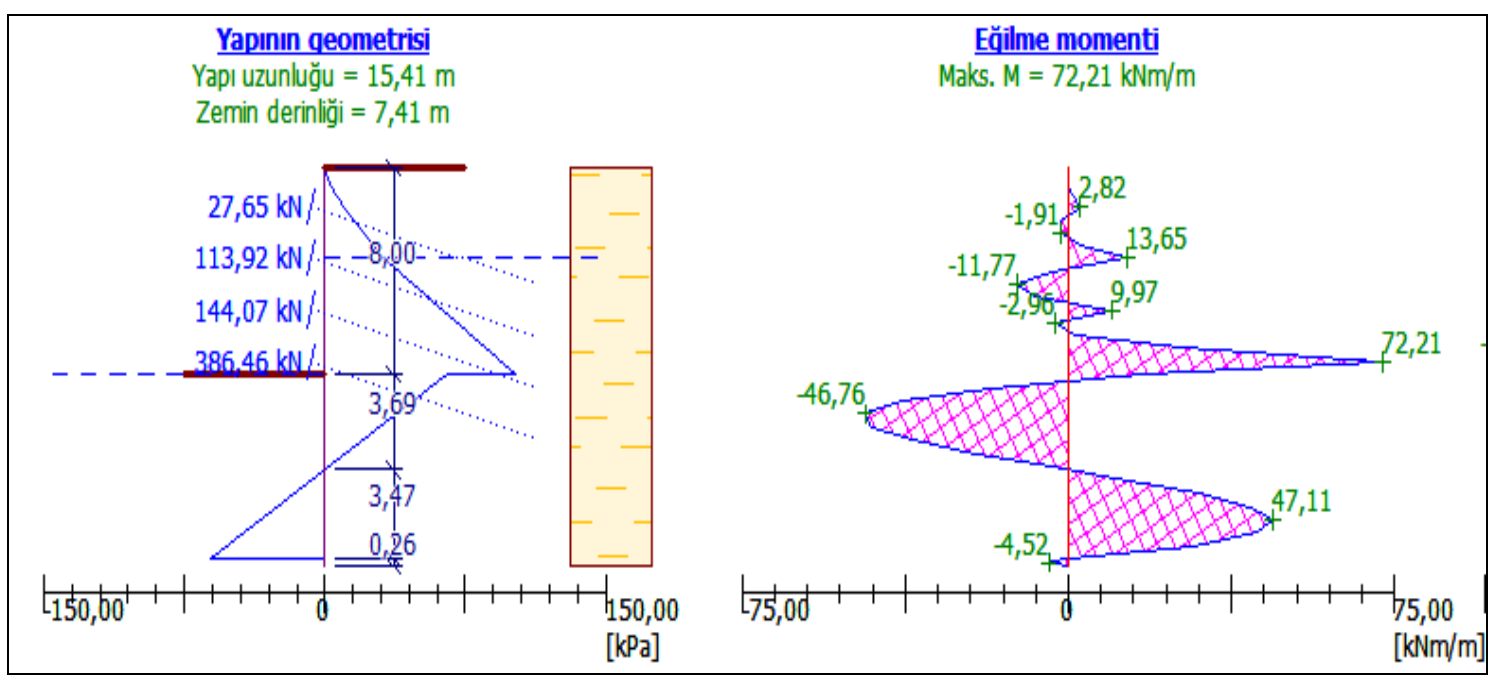

Şekil 4. Geo5 perde tasarımı analiz sonuçları (EN1997-DA3-Model-1). 


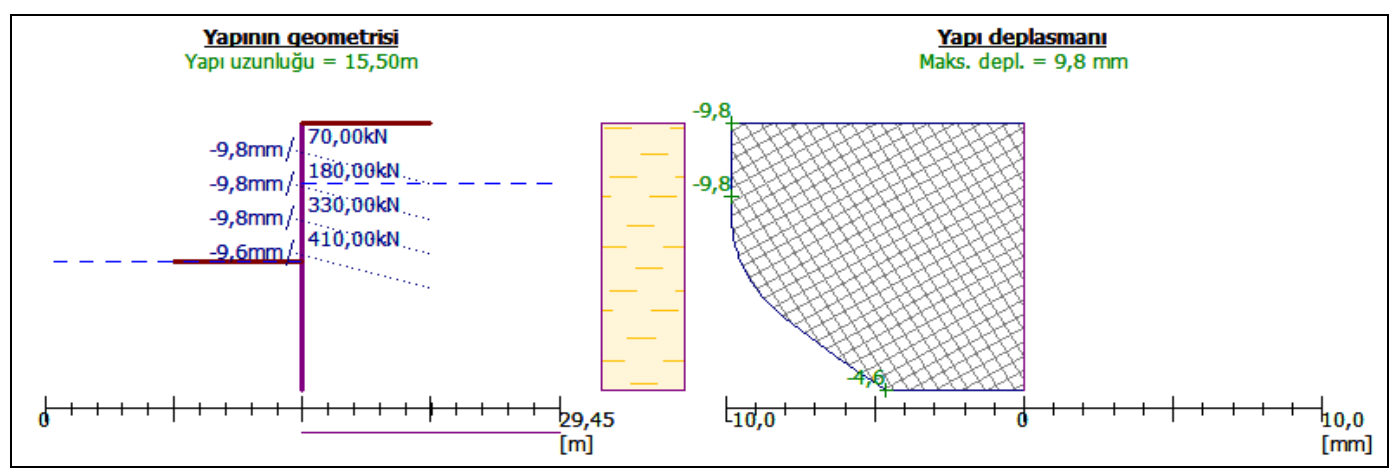

Şekil 5. Geo5 perde kontrolü-Deformasyonlar-8. aşama (EN1997-DA3-Model-1).

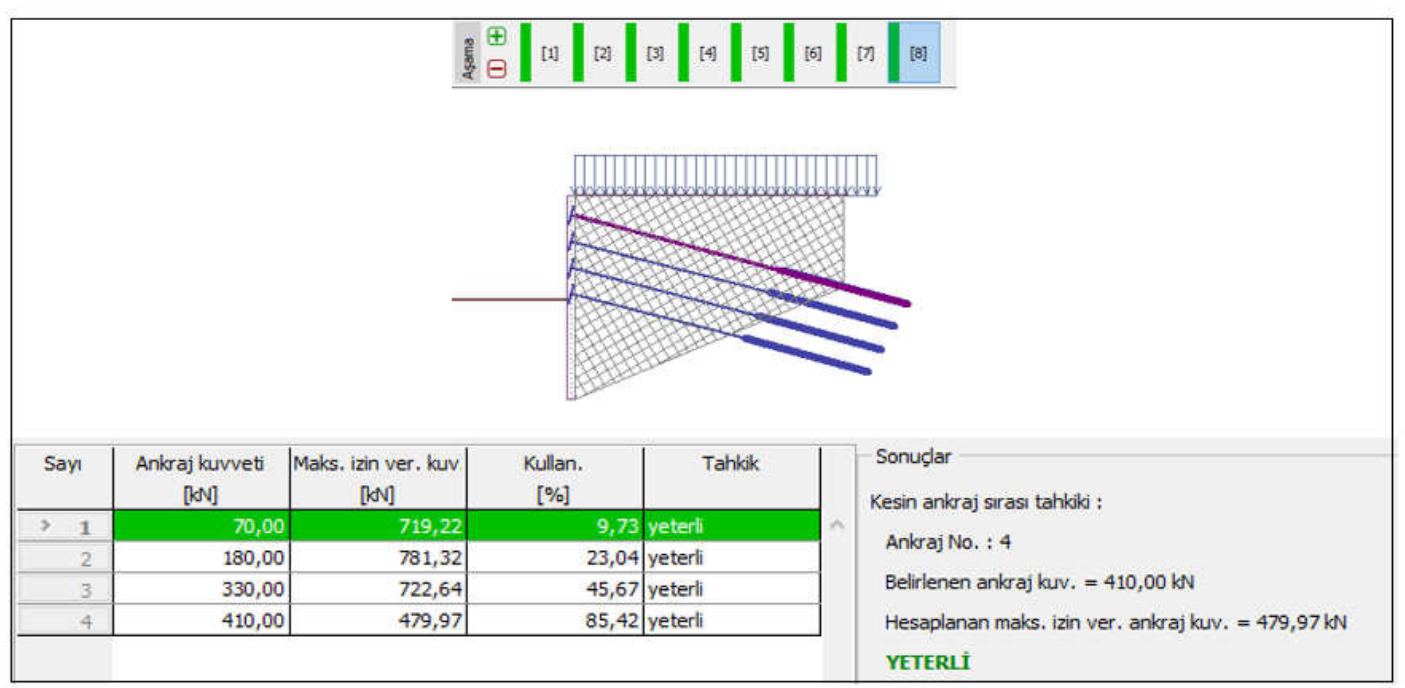

Şekil 6. Geo5 perde kontrolü-İçsel stabilite-8. aşama (EN1997-DA3 - Model-1).

Tablo 9. Geo5 analiz sonuçları.

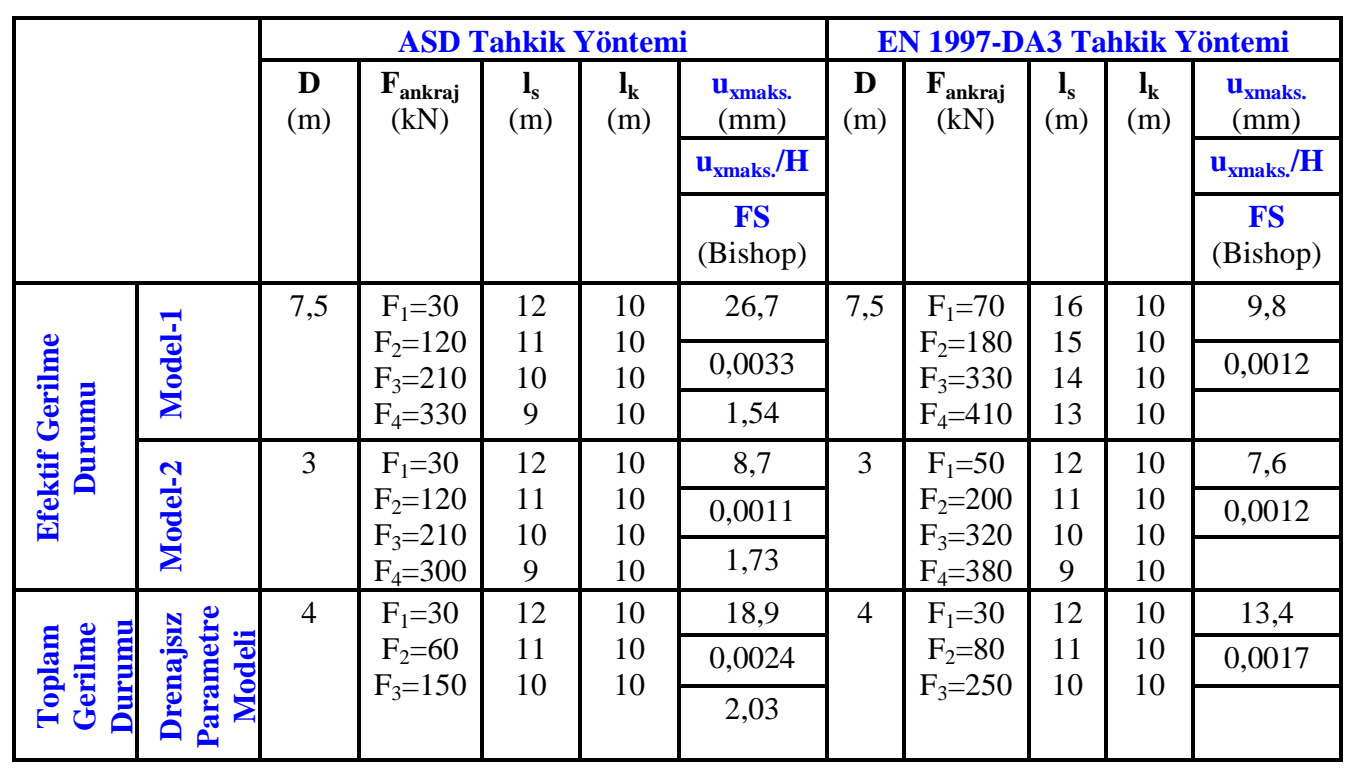


Geo5' de her bir inşaat aşaması için deplasman ve içsel stabilite dengelerinin kontrol edilmesiyle tasarlanan çok sıra ankrajlı sistemin (Tablo 10-11) Plaxis ile analizinde, $\mathrm{B}=30 \mathrm{~m}$ kazı genişliği kabulü yapılmış, sınır şartları $\mathrm{x}_{\text {maks. }}=150 \mathrm{~m}$ ve $\mathrm{y}_{\min }=-120 \mathrm{~m}$ belirlenmiştir. Plaxis ile 9 aşamalı olarak düzenlenen sistemlerin deformasyon analizleri ve güvenlik analizleri $\left(\mathbf{M}_{\mathrm{sf}}\right)$ yapılmıştır (Şekil 7, Tablo 12).

Tablo 10. Plaxis programı ankraj parametreleri.

\begin{tabular}{|c|c|c|c|c|c|c|c|c|}
\hline \multicolumn{5}{|c|}{ Halat Kismı } & \multicolumn{4}{|c|}{ Kök Kısmı } \\
\hline $\begin{array}{c}\text { L } \\
\text { Uzunluk } \\
(\mathbf{m}) \\
\end{array}$ & $\begin{array}{c}\text { A } \\
\text { Alan } \\
\left(\mathbf{m}^{2}\right) \\
\end{array}$ & $\begin{array}{c}\mathbf{E} \\
\text { Elastisite } \\
\text { Modülü } \\
\left(\mathbf{k N} / \mathbf{m}^{2}\right) \\
\end{array}$ & $\begin{array}{c}\text { EA } \\
\text { Normal } \\
\text { Rijitlik } \\
(\mathbf{k N}) \\
\end{array}$ & $\begin{array}{c}\mathbf{L}_{\text {spacing }} \\
\text { Aralık } \\
\text { (m) } \\
\end{array}$ & $\begin{array}{c}\mathbf{L}_{\text {kök }} \\
\text { Uzunluk } \\
(\mathbf{m}) \\
\end{array}$ & $\begin{array}{c}\text { D } \\
\text { Çap } \\
(\mathbf{m}) \\
\end{array}$ & $\begin{array}{c}\mathrm{E} \\
\text { Elastisite } \\
\text { Modülü } \\
\left(\mathbf{k N} / \mathbf{m}^{2}\right) \\
\end{array}$ & $\begin{array}{r}\mathbf{L}_{\text {spacing }} \\
\text { Aralık } \\
\text { (m) } \\
\end{array}$ \\
\hline 12 & $2 \times 0,001$ & 210000000 & 42000 & 1,5 & 10 & 0,15 & 20000000 & 1,5 \\
\hline 11 & $2 \times 0,001$ & 210000000 & 42000 & 1,5 & 10 & 0,15 & 20000000 & 1,5 \\
\hline 10 & $2 \times 0,001$ & 210000000 & 42000 & 1,5 & 10 & 0,15 & 20000000 & 1,5 \\
\hline 9 & $2 \times 0,001$ & 210000000 & 42000 & 1,5 & 10 & 0,15 & 20000000 & 1,5 \\
\hline
\end{tabular}

Tablo 11. Plaxis programı duvar parametreleri.

\begin{tabular}{|c|c|c|c|c|c|}
\hline $\begin{array}{c}\text { d } \\
\text { Duvar } \\
\text { Kalınlığı } \\
(\mathbf{m}) \\
\end{array}$ & $\begin{array}{c}\text { E } \\
\text { Elastisite } \\
\text { Modülü } \\
\left(\mathbf{k N} / \mathbf{m}^{2}\right) \\
\end{array}$ & $\begin{array}{c}\text { EA } \\
\text { Normal } \\
\text { Rijitlik } \\
(\mathbf{k N}) \\
\end{array}$ & $\begin{array}{c}\text { EI } \\
\text { Eğilme } \\
\text { Rijitliği } \\
\left(\mathbf{k N m}^{2}\right) \\
\end{array}$ & $\begin{array}{c}v \\
\text { Poisson } \\
\text { Oranı }\end{array}$ & $\begin{array}{c}\text { w } \\
\text { Duvar Birim } \\
\text { A ğırlığ } \\
(\mathbf{k N} / \mathbf{m} / \mathbf{m}) \\
\end{array}$ \\
\hline 1 & 31.000 .000 & 31.000 .000 & 2.583 .333 & 0,15 & 12,5 \\
\hline
\end{tabular}
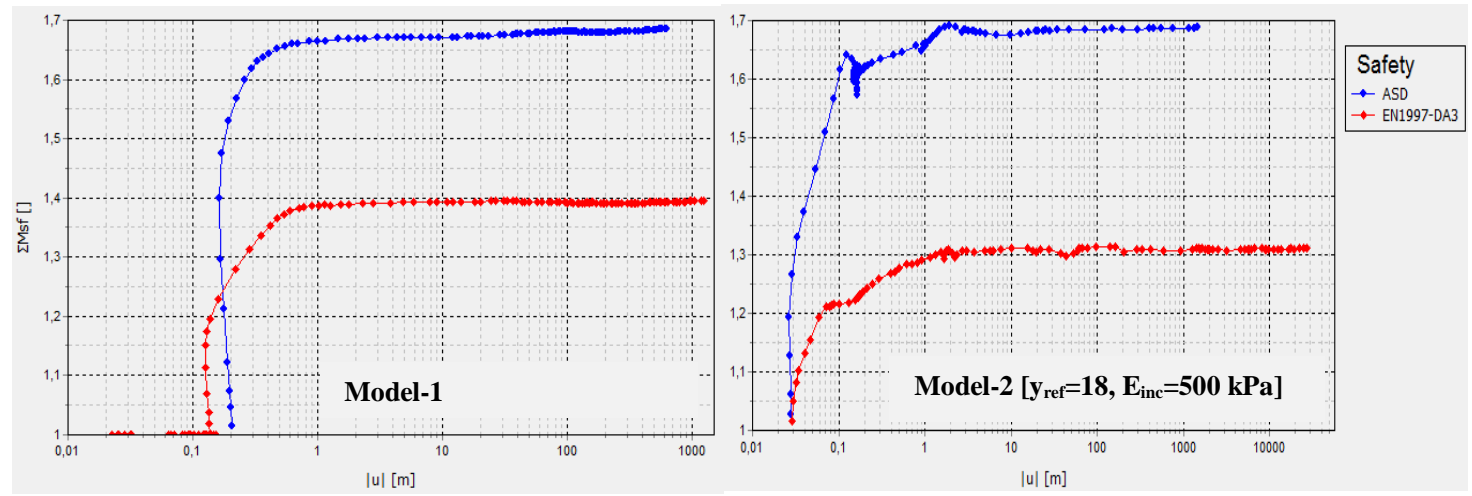

Şekil 7. Plaxis güvenlik analizi $\left(\mathrm{M}_{\mathrm{sf}}\right)$ sonucu.

Geo5 drenajsız parametrelere dayalı toplam gerilme analizinde deformasyonlar; $u_{\text {xmaks. }}=18,9 \mathrm{~mm}$ (ASD) ve $u_{\text {xmaks. }}=13,40 \mathrm{~mm}$ (EN1997-DA3) elde edilmiş iken, Plaxis drenajsız parametrelere dayalı drenajsız analizinde, rijitliğin derinlik ile arttığı varsayımında dahi deformasyonlar $u_{x m a k s .}=49 \mathrm{~mm}$ (ASD) ve $u_{x m a k s .}=88 \mathrm{~mm}$ (EN1997DA3) belirlenmiştir. Sonuçlar arasında halen önemli bir fark oluşu, Geo5 programının sınır şartlarını ve kazı genişliğini dikkate almaması ve analiz sonuçlarında bulunan maximum deplasmanların yerlerinin farklı olması ile açıklanabilir.

Plaxis analizlerinin sonucu yalnızca Model-2 ( $\left.\mathrm{y}_{\text {ref }}=18 \mathrm{~m}, \quad \mathrm{E}_{\text {inc }}=500 \mathrm{kPa}\right)$ için oluşturulmuş efektif parametreler ile drenajsız analiz sonuçları sınır değerlerin altında çıkmıştır. $\mathrm{Bu}$ sonuç Plaxis ile yapılan analizlerde daha gerçekçi sonuçlar elde edilebilmesi için seçilen parametrelerin önemini göstermektedir. 
Tablo 12. Çok sıra ankrajlı destek sistemleri için Plaxis analiz sonuçları.

\begin{tabular}{|c|c|c|c|c|c|c|c|c|c|c|c|c|}
\hline & \multicolumn{5}{|c|}{ ASD Tahkik Yöntemi } & \multicolumn{5}{|c|}{ EN 1997-DA3 Tahkik Yöntemi } \\
\hline & & & \multirow[t]{3}{*}{$\begin{array}{c}\mathbf{D} \\
(\mathrm{m})\end{array}$} & \multirow[t]{3}{*}{$\begin{array}{c}\mathbf{F}_{\text {ankraj }} \\
(\mathrm{kN})\end{array}$} & \multirow[t]{3}{*}{$\begin{array}{c}\mathbf{l}_{\mathbf{s}} \\
(\mathrm{m})\end{array}$} & \multirow[t]{3}{*}{$\begin{array}{c}\mathbf{l}_{\mathbf{k}} \\
(\mathrm{m})\end{array}$} & $\begin{array}{c}\mathbf{u}_{\text {xmaks. }} \\
(\mathrm{mm})\end{array}$ & \multirow[t]{3}{*}{$\begin{array}{c}\text { D } \\
(\mathrm{m})\end{array}$} & \multirow[t]{3}{*}{$\begin{array}{c}\mathbf{F}_{\text {ankraj }} \\
(\mathrm{kN})\end{array}$} & \multirow[t]{3}{*}{$\begin{array}{c}\mathbf{l}_{\mathrm{s}} \\
(\mathrm{m})\end{array}$} & \multirow[t]{3}{*}{$\begin{array}{l}\mathbf{l}_{\mathbf{k}} \\
(\mathrm{m})\end{array}$} & $\begin{array}{c}\mathbf{u}_{\text {xmaks. }} \\
(\mathrm{mm})\end{array}$ \\
\hline & & & & & & & $\mathbf{u}_{\mathrm{xmaks}} . \mathbf{H}$ & & & & & $\mathbf{u}_{\text {xmaks. }} / \mathbf{H}$ \\
\hline & & & & & & & $\mathbf{M}_{\mathrm{sf}}$ & & & & & $M_{s f}$ \\
\hline \multirow{12}{*}{ 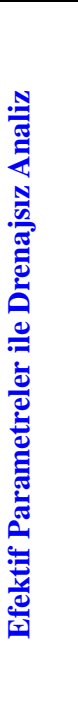 } & \multirow{3}{*}{\multicolumn{2}{|c|}{ 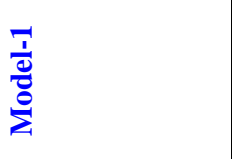 }} & \multirow[t]{3}{*}{7,5} & \multirow{3}{*}{$\begin{aligned} \mathrm{F}_{1} & =30 \\
\mathrm{~F}_{2} & =120 \\
\mathrm{~F}_{3} & =210 \\
\mathrm{~F}_{4} & =330\end{aligned}$} & \multirow{3}{*}{$\begin{array}{c}12 \\
11 \\
10 \\
9\end{array}$} & \multirow{3}{*}{$\begin{array}{l}10 \\
10 \\
10 \\
10\end{array}$} & 171 & \multirow[t]{3}{*}{7,5} & \multirow{3}{*}{$\begin{array}{c}\mathrm{F}_{1}=70 \\
\mathrm{~F}_{2}=180 \\
\mathrm{~F}_{3}=330 \\
\mathrm{~F}_{4}=410\end{array}$} & \multirow{3}{*}{$\begin{array}{l}16 \\
15 \\
14 \\
13\end{array}$} & \multirow{3}{*}{$\begin{array}{l}10 \\
10 \\
10 \\
10\end{array}$} & 192 \\
\hline & & & & & & & 0,0214 & & & & & 0,024 \\
\hline & & & & & & & 1,69 & & & & & 1,40 \\
\hline & \multirow{3}{*}{ 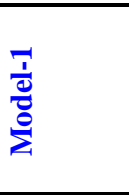 } & \multirow{3}{*}{ 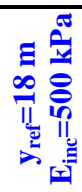 } & \multirow{3}{*}{7,5} & \multirow{3}{*}{$\begin{aligned} \mathrm{F}_{1} & =30 \\
\mathrm{~F}_{2} & =120 \\
\mathrm{~F}_{3} & =210 \\
\mathrm{~F}_{4} & =330\end{aligned}$} & \multirow{3}{*}{$\begin{array}{c}12 \\
11 \\
10 \\
9\end{array}$} & \multirow{3}{*}{$\begin{array}{l}10 \\
10 \\
10 \\
10\end{array}$} & 49 & \multirow[t]{3}{*}{7,5} & \multirow{3}{*}{$\begin{array}{c}\mathrm{F}_{1}=70 \\
\mathrm{~F}_{2}=180 \\
\mathrm{~F}_{3}=330 \\
\mathrm{~F}_{4}=410\end{array}$} & \multirow{3}{*}{$\begin{array}{l}16 \\
15 \\
14 \\
13\end{array}$} & \multirow{3}{*}{$\begin{array}{l}10 \\
10 \\
10 \\
10\end{array}$} & 55 \\
\hline & & & & & & & 0,0061 & & & & & 0,0069 \\
\hline & & & & & & & 1,68 & & & & & 1,39 \\
\hline & \multirow{3}{*}{\multicolumn{2}{|c|}{ 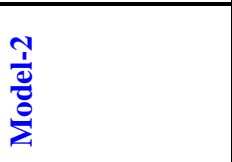 }} & 3 & $\mathrm{~F}_{1}=30$ & 12 & 10 & 63 & 3 & $\mathrm{~F}_{1}=50$ & 12 & 10 & 75 \\
\hline & & & & $\begin{array}{l}F_{2}=120 \\
\end{array}$ & 11 & $\begin{array}{l}10 \\
10\end{array}$ & 0,0079 & & $\mathrm{~F}_{2}=200$ & 11 & 10 & 0,0093 \\
\hline & & & & $\mathrm{F}_{4}=300$ & 9 & 10 & 1,71 & & $\mathrm{~F}_{4}=380$ & 9 & 10 & 1,32 \\
\hline & & $\Xi \approx$ & 3 & $\mathrm{~F}_{1}=30$ & 12 & 10 & 33 & 3 & $\mathrm{~F}_{1}=50$ & 12 & 10 & 38 \\
\hline & $\frac{1}{2}$ & 舫 & & $\begin{array}{l}F_{2}=120 \\
F_{2}=210\end{array}$ & $\begin{array}{l}11 \\
10\end{array}$ & $\begin{array}{l}10 \\
10\end{array}$ & 0,0041 & & $\begin{array}{l}\mathrm{F}_{2}=200 \\
\mathrm{~F}_{3}=320\end{array}$ & $\begin{array}{l}11 \\
10\end{array}$ & $\begin{array}{l}10 \\
10\end{array}$ & 0,0048 \\
\hline & $\stackrel{e}{\Sigma}$ & 贵 & & & 9 & 10 & 1,69 & & & 9 & 10 & 1,31 \\
\hline$\cong$ & $\Xi \ldots$ & & 4 & $F_{1}=30$ & 12 & 10 & 83 & 4 & $F_{1}=30$ & 12 & 10 & 174 \\
\hline 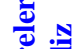 & 彦 & & & & 11 & 10 & 0,0104 & & & 11 & 10 & 0,0218 \\
\hline 焉元 & 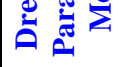 & & & & & & 1,8 & & & & & 1,25 \\
\hline$\approx \frac{\Delta}{\pi}$ & & $=\tilde{\pi}$ & 4 & $\mathrm{~F}_{1}=30$ & 12 & 10 & 49 & 4 & $\mathrm{~F}_{1}=30$ & 12 & 10 & 88 \\
\hline 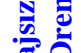 & 焉 & $\infty 8$ & & $\begin{array}{l}\mathbf{F}_{2}=00 \\
F_{3}=150\end{array}$ & 10 & 10 & 0,0061 & & $\mathrm{~F}_{3}=250$ & 10 & 10 & 0,0110 \\
\hline 离 & $\tilde{\bar{\Delta}} \approx$ & 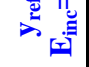 & & & & & 1,8 & & & & & 1,25 \\
\hline
\end{tabular}

\section{Sonuçlar}

Bu çalışmada geoteknik problemler için çözüm sağlayan ancak hesap yöntemi açısından farklı iki ayrı yazılım (Geo5 ve Plaxis) kullanılarak, geoteknik modellemenin farklı derin kazı destek sistemlerinin performansı üzerindeki etkisi incelenmiştir. Balıkesir'deki inceleme alanı için olușturulan alternatif geoteknik modellerin ilki, hâkim zemin tabakaları, bu tabakalara ait arazi ve laboratuvar deneyleri ve literatürdeki mevcut ampirik ilişkiler göz önüne alındığında; drenajsız parametrelere dayanmaktadır. Diğer ikisi ise aynı zemin koşulları için oluşturulmuş efektif parametre modelleridir. Çalışmada, geoteknik modellemenin efektif parametrelere dayalı olarak yapılmasının daha uygun olacağının belirlendiği söylenebilir.

Efektif parametre modelleri drenajsız parametre modeli ile Geo5 ve Plaxis deformasyon analiz sonuçlarının uyumu cinsinden kıyaslanarak, inceleme alanını en iyi temsil eden efektif parametre modeli belirlenmeye çalışılmıştır. Çalışmada hesap yöntemleri 
açısından farklı iki ayrı yazılımın kullanılıyor olması da modellemenin önemini daha fazla ön plana çıkarmış bulunmaktadır.

$\mathrm{Bu}$ çalışmada göz önüne alınan zemin koşulları için yapılan modellemelere dayalı olarak 4 m kazı derinliği için dahi konsol destek sisteminin uygulanabilir olmadığı ve ankraj gibi yatay destek elemanlarına ihtiyaç olduğu söylenebilir. Deformasyonların belirlenmesinde Geo5 programı ile Plaxis programını karşılaştırdığımızda, bir sonlu elemanlar yazılımı olan Plaxis ile yapılan analizlerde daha gerçekçi çözümlere ulaşılabilmesinde, seçilen parametrelerin çok önemli olduğu ve daha detaylı veriye dayalı geoteknik modellere ihtiyacımız olduğu görülmüştür.

\section{Kaynaklar}

[1] Demirkoç, A., Derin Kazılarda Zemin Çivisi ile Ankrajlı Destek Sistemlerinin Karşılaştırılmalı Analizi, Yüksek Lisans Tezi, Yıldız Teknik Üniversitesi Fen Bilimleri Enstitüsü, İnşaat Mühendisliği Anabilim Dalı, İstanbul, (2007).

[2] Tunca, M., Derin Kazılardan Kaynaklanan Zemin Oturmalarının Sayısal Analizlerle İncelenmesi, Yüksek Lisans Tezi, Yıldız Teknik Üniversitesi Fen Bilimleri Enstitüsü, İnşaat Mühendisliği Anabilim Dalı, İstanbul, (2010).

[3] Çetin, Z., Derin Kazı Yüzeyi Desteklenmesinin Sonlu Eleman Modelleriyle Analizi, Yüksek Lisans Tezi, Anadolu Üniversitesi Fen Bilimleri Enstitüsü, İnşaat Mühendisliği Anabilim Dalı, Eskişehir, (2012).

[4] Engin, V., Limit Denge Metodu ile Elde Edilen Güvenlik Katsayısının Sonlu Elemanlar Yönteminde Kullanılan Dayanım Azaltma Katsayısı ile Karşılaştırılması, Yüksek Lisans Tezi, Orta doğu Teknik Üniversitesi Fen Bilimleri Enstitüsü, İnşaat Mühendisliği Anabilim Dalı, Ankara, (2012).

[5] Cengiz, A.D., Bir Diyafram Duvarda Tahmin Edilen ve Ölçülen Yer Değiştirmelerin Karşılaştırılması, Yüksek Lisans Tezi, Yıldız Teknik Üniversitesi Fen Bilimleri Enstitüsü, İnşaat Mühendisliği Anabilim Dalı, İstanbul, (2008).

[6] Bahar, M., Diyafram Duvarlı İksa Perdelerinde Ölçülen ve Tahmin Edilen Deplasmanların Karşılaştırılması, Yüksek Lisans Tezi, Yıldız Teknik Üniversitesi Fen Bilimleri Enstitüsü, İnşaat Mühendisliği Anabilim Dalı, İstanbul, (2009).

[7] Ermanlar, L., Derin Kazılar Sonucu Çevre Yapılarda Oluşan Deformasyonların Tahmini, Yüksek Lisans Tezi, Yıldız Teknik Üniversitesi Fen Bilimleri Enstitüsü, İnşaat Mühendisliği Anabilim Dalı, İstanbul, (2009).

[8] Özberk, B.S., Ankraj Destekli Derin İksalarda Deformasyonların İncelenmesi, Yüksek Lisans Tezi, Yıldız Teknik Üniversitesi Fen Bilimleri Enstitüsü, İnşaat Mühendisliği Anabilim Dalı, İstanbul, (2009).

[9] Sevencan, O., Açık Derin Kazılarda Zemin Deformasyonlarının Nümerik Analizi, Yüksek Lisans Tezi, Yıldız Teknik Üniversitesi Fen Bilimleri Enstitüsü, İnşaat Mühendisliği Anabilim Dalı, İstanbul, (2009).

[10] Aktan, E., Öngermeli Ankrajlı Kazıklı Duvar Nümerik Analizi: Hilton İstanbul Bomonti Hotel ve Konferans Merkezi Projesi Kapsamında Yer Alan Tarihi Bina Önü İksa Sistemi, Yüksek Lisans Tezi, İstanbul Teknik Üniversitesi Fen Bilimleri Enstitüsü, İnşaat Mühendisliği Anabilim Dalı, İstanbul, (2014).

[11] Sert, S., Önalp, A., Arel, E., Sayısal Çözümlerde Zemin Özelliklerindeki Değişimin Sonuçlara Etkisi, ZMTM 13. Ulusal Kongresi, sf: 471-482, İKÜ, İstanbul, (2010).

[12] Sert, S., Önalp, A., Derin Kazılarda Hassaslık ve Parametre Değişimi Analizi, 4. Geoteknik Sempozyumu, ÇÜ, Adana, (2011). 
[13] Bildik, S., Uncuoğlu, E., Laman, M., Suleiman, M.T., Yüzeysel Temellerin Sayısal Modellemesinde Zemin Parametrelerinin Etkisi, ZMTM 14. Ulusal Kongresi, sf: 367-474, SDÜ, Isparta, (2012).

[14] Sert, S., Luo, Z., Xiao, J., Gong, W. and Juang, C. H., Probabilistic analysis of responses of cantilever wall-supported excavations in sands considering vertical spatial variability. Computers and Geotechnics 75, 182-191. (2016).

[15] Geo5, User's Guide, Geotechnical Software, Fine Ltd. (2015).

[16] Plaxis Delft University of Technology \& Plaxis bv, Delft, The Netherlands. (2014).

[17] Aslan, V., Derin Kazıların Sayısal Analizi için Parametrik bir Çalışma, Yüksek Lisans Tezi, Balıkesir Üniversitesi, Fen Bilimleri Enstitüsü, İnşaat Mühendisliği Ana Bilim Dalı, Balıkesir, (2017).

[18] Erol, A.O. ve Çekinmez, Z., Geoteknik Mühendisliğinde Saha Deneyleri, Ankara, Yüksel Proje Yayınları, (2014). 